https://doi.org/10.48009/2_iis_2008_412-420

\title{
A COMPARISON OF STUDENT USE AND UNDERSTANDING OF TEXT MESSAGING SHORTHAND AT TWO UNIVERSITIES
}

\author{
Betty A. Kleen, Nicholls State University, betty.kleen@nicholls.edu \\ Lynn Heinrichs, Elon University, $\underline{\text { heinrichs@elon.edu }}$
}

\begin{abstract}
Text and instant messaging have introduced a new shorthand vocabulary for communication in today's world. Yet, little research has been done to-date on how much it is used and understood. The current study examines student use and understanding of text messaging acronyms and shorthand at two universities. A questionnaire was administered to students enrolled in the introductory MIS course at both schools. Data were collected regarding text messaging practices, perception of appropriateness, and shorthand interpretation. Results are analyzed and discussed along with implications for future research.
\end{abstract}

Keywords: text messaging, cell phones, acronyms, shorthand

\section{INTRODUCTION}

While text messaging using cell phones may have originated less than 20 years ago [19], according to the International Association for the Wireless Telecommunications Industry, wireless users sent 18.66 billion text messages in the U.S. in December of 2006 alone [22]. The numbers are increasing at a dramatic rate-more than 64.8 billion text messages were sent in the first six months of 2006, and over 158 billion text messages were sent in all of 2006 in the U.S., representing an increase of $95 \%$ over 2005 statistics [3]. Statistics provided by cellsigns.com [22] reflect that over $98 \%$ of all cell phones have SMS, the universal mobile platform. While recent reports indicate that four phone calls are made for every text message sent, the ratio is shrinking [26]. The technology capabilities and trends suggest that text messaging will continue to grow at a rapid rate. To support this projection, IDC, a research company that tracks technology and consumer research, projects that 81 percent of Americans ages 5 to 24 will own a cell phone by 2010 [9].

Text messaging articles indicate that millennials (people born after 1980) are the largest group of users of text messaging [22]. Prater [19] reports that some students occasionally prefer to use text messages at times instead of voice communication through cell phones as a way to circumvent those on the phone who will not stop talking. Holson [9] reports that teens may also send text messages even when seated side by side so that others will not hear a conversation. Cell phones also allow the convenience of being able to text someone while in class, in meetings, etc., as teens and other frequent "texters" can skillfully text with a hand in a pocket while appearing to be engrossed in listening or some other task [19].

In addition to all the personal uses of cell phone text messages, businesses report productivity gains are possible by using computer IM instead of email. MacSweeney [14] suggests instant messaging usage often starts as a grassroots movement within an organization and evolves to pervade the corporate workplace. "Instant messaging applications expand," [10] reported that close to one-third of U.S. banks use some form of IM and that numbers such as this prove IM is a big deal. Dolan [5], writing in amednews, the newspaper for America's physicians, reports that texting is expected to become more common in the medical field as more medical students are familiar with texting; while not anticipated for use in substantive patient issues, a phone consult might be requested with PCM (please call me).

\section{ACRONYMS AND SHORTHAND}

Acronyms, abbreviations used in writing that have typically been pronounced as a word (such as SNAFU, representing "situation normal, all fouled up"), and shorthand pronunciations that say the letter one by one (such as I M H O for "in my humble opinion"), are used extensively in text messaging and instant messaging. Malala [15] notes that those communicating through both online instant messaging and cell phone text messaging use the same word list or dictionary of acronyms and shorthand. A Google search of "text message acronyms" will identify hundreds of sites that provide information about them. Sites such as Netlingo.com [13, 20], MIstupid.com [2], Webopedia.com [21], and Pulpchat.com [6] provide lists of some of the more commonly used acronyms and shorthand. 
Although acronyms and shorthand are reported as very popular in instant and text messaging, not all people send and/or receive instant or text messages. For those individuals, the acronyms and shorthand may encourage miscommunication. However, computer savvy adults may remember the days when WYSIWYG was used extensively instead of "what you see is what you get" to discuss word processing software capabilities. Also, many will recall a time when FYI, meaning "for your information," was used extensively in and out of business offices. Some of the acronyms being used today by individuals doing instant messaging or text messaging may be easier to interpret correctly than others. For example, the acronyms and accompanying meanings listed below all came from Netlingo.com [13], Webopedia.com [21], or Publchat.com [6].

$\begin{array}{lll}\text { - } & \mathrm{U} & \text { you } \\ \text { - } & \mathrm{l} r & \text { later } \\ \text { - } & \text { bf } & \text { boyfriend } \\ \text { - } & \mathrm{gf} & \text { girlfriend } \\ \text { - } & \text { brb } & \text { be right back } \\ \text { - } & \mathrm{sry} & \text { sorry } \\ \text { - } & \mathrm{lol} & \text { laugh out loud } \\ \text { - } & \text { gtg } & \text { got to go } \\ \text { - } & \mathrm{idk} & \text { I don't know } \\ \text { - } & \text { pos } & \text { parent over shoulder } \\ \text { - } & \text { eg } & \text { evil grin } \\ \text { - } & \text { tbh } & \text { to be honest } \\ \text { - } & \text { lerk } & \text { leaving easy reach of keyboard } \\ \text { - } & \text { ficcl } & \text { frankly, I couldn't care less } \\ \text { - } & \text { dbeyr } & \text { don't believe everything you read } \\ \text { - } & \text { wiifm } & \text { what's in it for me? } \\ \text { - } & 143 & \text { I love you }\end{array}$

Some of the above could be rather difficult to interpret correctly, even within the context of the full message being sent.

To further support the significance of IM and text message acronyms and shorthand, Pulpchat.com makes reference to a pseudo-language, and Webopedia.com refers to an emerging new language. Holson [9] suggests text messaging has become this generation's version of pig latin. Sites such as noslang.com [11] even provide help for those unfamiliar with texting acronyms by allowing a visitor to enter an acronym and translating it into slang free language.

To further confuse those who may be called upon to decode texting acronyms or offer an opinion as to whether the language is being degraded, eweek.com reports that "textonyms" can further challenge a reader [23]. Textonyms are replacement words that are first alternatives that come up on a mobile phone using predictive text (such as changing "cool" into "book"). The article suggests textonyms are simply among the latest linguistic creations that young people have devised over various generations.

Despite the recent media attention to text messaging and discussion of the meaning of various acronyms, Genn [7] suggests using them in text and instant messaging does not work well in the workplace and is contributing to communications breakdown. Malala [15] also notes that while many who send text messages are aware of acronym shortcuts, many others are not. For example, even in a business environment, unless the recipient knows CTRN means "can't talk right now," miscommunication will occur. Prater [19] suggests it may be too soon to think of text messaging acronyms as a language all its own. Widhalm [28], writing in the Washington DC Times, notes that it remains under debate as to whether the English language is deteriorating "IRL" - in real life. In the same article, a representative of the Loudoun County Public schools offers the opinion that students do know when and where to use texting acronyms and shorthand appropriately; acronyms and shorthand might appear in a rough draft, but not in a final draft.

Malala [15], on the other hand, makes a case for formalizing the acronyms used in text and instant messaging to meet global demands. While he cites limited published research in U.S. academic journals related to acronyms and lingo of text and instant messaging, he does cite some studies from other parts of the world. Malala suggests there is no indication that these new acronyms and shorthand will disappear. Instead, he believes most people will eventually use the new acronyms as part of their normal business communication when telecommuting since those who text frequently can use just two or three acronyms to write the equivalent of a long sentence.

An extensive literature search of databases such as Business Source Complete, Academic Search Complete, ERIC, PsychInfo, and Psych \& Behavioral Science Collection revealed little in the way of research studies with concrete data of teenagers' use of acronyms and shorthand in either instant messaging or text messaging. The current researchers suspect that this lack of data-driven studies may be in part because of additional research constraints when studying minor age children. While some studies may be in process, very little has yet 
been printed in academic journals regarding acronyms and shorthand in IM and text messaging.

A number of studies have focused more on youths' use of the Internet as a social medium. Studies have been completed that investigate such issues as compulsive Internet use and psychosocial well-being among young people [25]. Behairy, Mukherjee, Ertimur, and Venkatesh [1] used semi-structured indepth interviews of 18-25 year olds and identified ways in which intimacy in social situations influenced the communication technologies young consumers used. Valkenburg, Schouten, and Peter [24] researched adolescents' use of the Internet, focusing on identity experiments. Mandell and Muncer [16] studied 18-20 year olds to determine why they used different communication media in their social lives and concluded that different communication media afforded participants various levels of control over their social interactions. Gross [8] reported on $7^{\text {th }}$ and $10^{\text {th }}$ graders' use of the Internet, drawing conclusions about online social interactions.

Jacobson [12] investigated context and meaning in computer-mediated communication (IM) among college students, both as senders and receivers of messages, although the study did not investigate use of acronyms and shorthand. While Zhou and Zhang [30] studied punctuation convention in instant messaging, their work did not include investigation of acronyms or shorthand.

While the magnitude of text messages exchanged annually is indeed expected to keep growing, and the use of text and instant messaging acronyms and shorthand is not expected to diminish, few related studies have yet appeared in the academic literature. Much of the information about acronyms and shorthand in instant or text messaging currently available either comes from trade publications and online sites that report their extensive use or focuses on other issues of youth Internet activities. Further research on use and knowledge of the acronym and shorthand of instant messaging and text messaging is therefore justified.

\section{RESEARCH QUESTIONS AND METHODOLOGY}

Because literature suggests that millennials (those born after 1980) are the biggest users of text messaging via cell phones and that acronyms and shorthand are used in their messages, the researchers designed this study to explore students' use and knowledge of text messaging acronyms and shorthand. The following specific research questions were identified:

- How many students use text messaging and how frequently?

- Why do students use acronyms and shorthand in text messages, and how do they perceive acronyms and shorthand impact communication?

- For what types of communications do students believe acronyms and shorthand are appropriate?

- Can students correctly identify the meaning of various often-used acronyms or shorthand when presented as stand-alone entries?

- Are the responses of students at different institutions significantly different?

The profiles of the two institutions used for the study are summarized in Table 1. Institution A is a public university whose student body is primarily in-state. Institution $\mathrm{B}$, on the other hand, is private with a largely out-of-state student body. The institutions are both predominately undergraduate with similar fulltime enrollments. Institution $A$ has a higher proportion of women than Institution B.

Table 1. University Profiles

\begin{tabular}{|l|l|l|}
\hline Characteristic & Institution A & Institution B \\
\hline Control & Public & Private \\
\hline Location & Deep South & Mid-Atlantic \\
\hline FT Enrollment & & \\
Undergrad & 4911 & 4939 \\
Grad/Prof. School & 152 & 517 \\
Total & 5063 & 5456 \\
\hline Gender (M/F) & $36 / 64 \%$ & $41 / 59 \%$ \\
\hline Undergrad & $95 \%$ & $28 \%$ \\
In-State & & \\
\hline
\end{tabular}

The researchers used a questionnaire to gather information concerning the above research questions which was previously pilot-tested at Institution A. The text messaging survey was administered to students in the introductory MIS course at both universities during the month of February 2008. The introductory MIS course is offered at the 200-level and required of all business students at both institutions. At both schools, the surveys were administered during regular class time; students received no "extra credit" for completing the surveys. All 182 students who participated provided usable survey data. 
The two-page survey instrument provided the following definitions for students to use in their responses:

- $\quad$ Text messaging - messages sent via cell phone keypads - limited to 160 characters.

- Instant messaging - originally computer based communication, requires computer or Internet access - communication in real time.

- Acronym - derived from first letters of a phrase, used to make the phrase easier to say and remember.

- Shorthand - character-saving abbreviation used in instant messaging or text messaging.

The first page of the survey contained items relating to demographics, cell phone practices, and the appropriateness of acronyms and shorthand usage for communication with different audiences using email, instant messaging, and text messaging. The second page of the survey contained 49 instant messaging abbreviations which respondents were asked to interpret. Of these 49, twenty were identified by Omnipod.com [17, 18] as top workplace acronyms. The remaining acronyms were some of those commonly appearing on lists at websites such as webopedia.com [21], mistupid.com [2], pulpchat.com [27], netlingo.com [13], and studentslackers.com [4]. Textonyms, as defined in "Textonyms give cell phone addicts a new language," [23] were not included in this particular study.

Survey responses were coded and entered into an MS-Excel spreadsheet. Frequency counts were calculated for correct responses. Two-tailed z-tests were used to determine whether or not the proportion of responses was significantly different. The z-test assumes "that a sample represents a random sample of the relevant population and that each group to be tested is independent of the other. It is not necessary for the two groups to have the same number of respondents [29]."

\section{DATA ANALYSIS AND FINDINGS}

As shown in Table 2, males outnumbered females at both Institution A (56.5\%) and B (67.6\%); the difference is not statistically significant. This likely reflects the larger proportion of men in most business programs. All of respondents from Institution B were in the traditional college age range of 18-24 while almost all $(88.9 \%)$ were in the same bracket at Institution A. The age difference is statistically significant.

Table 3 summarizes student responses regarding cell phone practices. Almost all Institution A students (98.1\%) and all of Institution B students routinely carried a cell phone. However, 7.4\% of Institution A students had not sent a text message; all of Institution B students had sent one. This difference is statistically significant.

The most frequent use of text messaging was several times a day for respondents at both institutions. However, this response was statistically $(\alpha=.10)$ more frequent at Institution B $(79.7 \%)$ vs. Institution A (65.7\%). Students at both institutions identified speed as the most important reason for using text messaging shorthand and acronyms. Participants at Institution B identified "more message in 160 characters" as important statistically more often than those at Institution A (20\% vs. 8\%). Neither group believed that text messaging frequently contributed to misunderstood communications.

Respondents were asked to indicate whether or not the use of acronyms and shorthand were appropriate for several communication methods to a variety of audiences. The results are shown in Table 4. Both groups believed they were appropriate to use with emails (89\% vs. 82\%) and text messages (98\% vs. $93 \%$ ) to families and friends. There was also support for the use of acronyms and shorthand in communications involving colleagues at work, but not at consistent levels. About one-fourth of respondents in each group (23\% vs. $28 \%$ ) thought acronyms and shorthand were appropriate for emails to colleagues at work. A larger proportion of students in both groups believed the practice was more appropriate for text messages and IMs to colleagues at work; however, respondents at Institution B saw the use as more appropriate statistically for instant messaging than those at Institution A (32\% vs. 57\%). There was little support for the practice with any communication to outsiders (customers, vendors, etc.) or supervisors, nor between students and teachers. 
Table 2. Gender and Age of Respondents

\begin{tabular}{|c|r|r|r|r|r|}
\hline \multirow{2}{*}{ Attribute } & \multirow{2}{*}{ Value } & \multicolumn{2}{|c|}{$\mathbf{A}(\mathrm{n}=108)$} & \multicolumn{2}{|c|}{$\mathbf{B}(\mathrm{n}=74)$} \\
\cline { 3 - 6 } & $\mathrm{M}$ & 61 & $56.5 \%$ & 50 & $67.6 \%$ \\
& $\mathrm{~F}$ & 46 & $42.6 \%$ & 24 & $32.4 \%$ \\
Gender & Unknown & 1 & $0.9 \%$ & 0 & $0.0 \%$ \\
\hline \multirow{3}{*}{ Age } & $\mathbf{1 8 - 2 4 *}$ & $\mathbf{9 6}$ & $\mathbf{8 8 . 9} \%$ & $\mathbf{7 4}$ & $\mathbf{1 0 0 . 0} \%$ \\
& $25-31$ & 7 & $6.5 \%$ & 0 & $0.0 \%$ \\
& $>=32$ & 4 & $3.7 \%$ & 0 & $0.0 \%$ \\
& Unknown & 1 & $0.9 \%$ & 0 & $0.0 \%$ \\
\hline
\end{tabular}

* Significant at a $95 \%$ confidence level $(\alpha=.05)$ using two-tailed z-test for proportions

Table 3. Cell Phone Practices

\begin{tabular}{|r|r|r|r|r|r|}
\hline \multirow{2}{*}{ Attribute } & Value & \multicolumn{2}{|c|}{ A (n=108) } & \multicolumn{2}{|c|}{ B (n=74) } \\
\cline { 3 - 6 } & Freq & \multicolumn{1}{c|}{ (n } & Freq & \multicolumn{1}{c|}{$\%$} \\
\hline Routinely Carry & Yes & 106 & $98.1 \%$ & 74 & $100.0 \%$ \\
a Cell Phone? & No & 2 & $1.9 \%$ & 0 & $0.0 \%$ \\
& Other/Blank & 0 & $0.0 \%$ & 0 & $0.0 \%$ \\
\hline Sent Text Messages Via & Yes* & $\mathbf{1 0 0}$ & $\mathbf{9 2 . 6 \%}$ & $\mathbf{7 4}$ & $\mathbf{1 0 0 . 0 \%}$ \\
a Cell Phone? & No & 8 & $7.4 \%$ & 0 & $0.0 \%$ \\
& Other/blank & 0 & $0.0 \%$ & 0 & $0.0 \%$ \\
\hline Frequency of & Several times/year & 6 & $5.6 \%$ & 0 & $0.0 \%$ \\
Text Messaging & Several times/month & 8 & $7.4 \%$ & 3 & $4.0 \%$ \\
& Several times/week & 15 & $13.9 \%$ & 10 & $13.5 \%$ \\
& Several times/day** & $\mathbf{7 1}$ & $\mathbf{6 5 . 7 \%}$ & $\mathbf{5 9}$ & $\mathbf{7 9 . 7 \%}$ \\
& Other/blank & 8 & $7.4 \%$ & 2 & $2.7 \%$ \\
\hline Most Important Reason & Fun to use & 6 & $5.6 \%$ & 0 & $0.0 \%$ \\
for Using IM or TM & Speedier & 71 & $65.7 \%$ & 43 & $58.1 \%$ \\
Shorthand and & More message* & $\mathbf{9}$ & $\mathbf{8 . 3 \%}$ & $\mathbf{1 5}$ & $\mathbf{2 0 . 3 \%}$ \\
Acronyms (Check all) & Do not use & 14 & $13.0 \%$ & 15 & $20.3 \%$ \\
& Other/blank & 8 & $7.4 \%$ & 1 & $1.4 \%$ \\
\hline Impact on & Easily understood & 40 & $37.0 \%$ & 30 & $40.5 \%$ \\
& Infrequently misund & 43 & $39.8 \%$ & 35 & $47.3 \%$ \\
& Frequently misund & 24 & $22.2 \%$ & 8 & $10.8 \%$ \\
& Other/blank & 1 & $0.9 \%$ & 1 & $1.4 \%$ \\
\hline
\end{tabular}

* Significant at a $95 \%$ confidence level $(\alpha=.05)$ using two-tailed z-test for proportions

$* *$ Significant at a $90 \%$ confidence level $(\alpha=.10)$; actual confidence level $=94.1$ 
Table 4. Acronyms and Shorthand Appropriateness

\begin{tabular}{|c|c|c|c|c|}
\hline \multirow{2}{*}{ Communication Method } & \multicolumn{2}{|c|}{$A(n=108)$} & \multicolumn{2}{|c|}{$B(n=74)$} \\
\hline & Freq & $\%$ & Freq & $\%$ \\
\hline IM (using computers) at work to colleagues* & 35 & $32 \%$ & 42 & $57 \%$ \\
\hline IM (using computers) at work to supervisors & 4 & $4 \%$ & 0 & $0 \%$ \\
\hline $\begin{array}{r}\text { IM (using computers) at work to outsiders } \\
\text { (customers, vendors, etc.) }\end{array}$ & 5 & $5 \%$ & 4 & $5 \%$ \\
\hline Email at work to colleagues & 25 & $23 \%$ & 21 & $28 \%$ \\
\hline Email at work to supervisors & 3 & $3 \%$ & 2 & $3 \%$ \\
\hline Email at work to outsiders & 5 & $5 \%$ & 3 & $4 \%$ \\
\hline Email to family and friends & 96 & $89 \%$ & 61 & $82 \%$ \\
\hline Email from student to teacher & 9 & $8 \%$ & 2 & $3 \%$ \\
\hline Email from teacher to student & 6 & $6 \%$ & 3 & $4 \%$ \\
\hline Text messaging to friends and family & 106 & $98 \%$ & 69 & $93 \%$ \\
\hline Text messaging at work to colleagues & 37 & $34 \%$ & 35 & $47 \%$ \\
\hline Text messaging at work to supervisors & 7 & $6 \%$ & 1 & $1 \%$ \\
\hline Text messaging at work to a customer & 7 & $6 \%$ & 1 & $1 \%$ \\
\hline
\end{tabular}

* Significant at a 95\% confidence level using two-tailed z-test for proportions

Table 5 summarizes the number of Total, Institution A, and Institution B respondents who correctly interpreted each text messaging shorthand or acronym. The table is sorted in descending order by the Total number of correct responses. In 27 cases, Institution B students interpreted the abbreviation more often (in terms of percentage); four of these were statistically significant at the 95\% confidence level (BRB, JK, THX, and UR) and two at the $90 \%$ level (SRY and CU). In 15 cases, Institution A students interpreted the abbreviation more often than Institution B (in terms of percentage); two of these were significant at a 90\% confidence level (LMAO and RFL?).

The most recognized acronym, LOL (laugh out loud), was identified by over $90 \%$ of students. This particular abbreviation is well-known even to nontexters. Other commonly known abbreviations included: BC (because), TTYL (talk to you later), BRB (be right back), PLZ (please), IDK (I don't know), and L8R (later). The following seven items were not identified correctly by any respondent and are not included in the table:
BFO: $\quad$ Blinding flash of the obvious
DHTB: Don't have the band width
GAL: $\quad$ Get a life
HTH: $\quad$ Hope this helps
IAM: $\quad$ In a meeting
OOH: $\quad$ Out of here
SLAP: $\quad$ Sounds like a plan

Although not reported in the table, the investigators also tracked the most incorrectly identified acronyms and shorthand. The four abbreviations that were misinterpreted the most were: B4N (23.6\%), ATM $(20.9 \%)$, POS $(19.8 \%)$, and B/F (15.9\%). In the case of B4N, the "B4" was often interpreted as "before" instead of "bye for." A similar mistake was often made for the meaning of $\mathrm{B} / \mathrm{F}$ as being "before." The acronym ATM was often equated to "automated teller machine," probably not a surprising result. The shorthand "POS" has received some attention in the media, and one might assume respondents would be familiar with its meaning. But, for college-age students the acronym appears to mean something else which the investigators will not elaborate on other than to say it begins with the word "piece."

In general, it appears that students at Institution B were more knowledgeable of text messaging abbreviations than students at Institution A, although all differences were not significant. This is probably not surprising given that a larger proportion of students from Institution B used text messaging and sent messages several times each day. The profile of Institution B's student body could partly explain this. More than $70 \%$ of students are from out-of-state; perhaps they use text messaging more often to stay in touch with people at home. Also, Institution B attracts an affluent population and students may be more able to pay for text messaging services. 


\section{CONCLUSIONS}

The purpose of the study was to compare text messaging shorthand use and understanding by students at two different universities, one public and one private. The results of the study provide a baseline to which future research efforts can compare.

As a whole, students at both institutions regularly carried cell phones and sent text messages. The primary reason for using text messaging shorthand and acronyms was speed; students most often sent text messages several times per day. The sending of messages several times a day supports the industry statistics that identify millennials as the major group of text messaging users.

Using abbreviations in communications with family and friends was deemed appropriate, but not with colleagues, customers, or vendors. Neither did students believe that acronyms and shorthand should be used between teachers and students. While the literature presents conflicting opinions as to whether the use of acronyms can negatively impact the language, students surveyed also have a variety of opinions on whether acronym usage contributes to communication misunderstanding.
There were differences between the two groups of respondents. About $11 \%$ of Institution A's participants were older than 21 as compared with none from Institution B. More students proportionately from Institution B text messaged several times per day. In general, students from Institution B also seemed to be more familiar with abbreviations. This finding would in part support Malala's [15] case for formalizing text messaging acronyms as more and more people will use them in the future.

\section{LIMITATIONS AND FUTURE DIRECTION}

The current study has some limitations that warrant further research. The samples from the two institutions were slightly different in size and age. Also, women were not well-represented because of the use of an introductory business class for administering the survey.

In the future, the researchers intend on addressing these limitations by including students at a third institution and moving beyond the introductory MIS course for data collection. The current study will provide a baseline to which these future efforts can be compared.

Table 5. Frequency of Correct Acronyms and Shorthand

\begin{tabular}{|c|c|c|c|c|c|c|c|}
\hline \multirow{2}{*}{$\begin{array}{l}\text { Acronym/ } \\
\text { Shorthand }\end{array}$} & \multirow{2}{*}{ Meaning } & \multicolumn{2}{|c|}{ Total } & \multicolumn{2}{|c|}{ A } & \multicolumn{2}{|c|}{ B } \\
\hline & & Freq & $\%$ & Freq & $\%$ & Freq & $\%$ \\
\hline LOL & Laugh out loud & 168 & $92.3 \%$ & 99 & $91.7 \%$ & 69 & $93.2 \%$ \\
\hline$B C, b / c$ & Because & 155 & $85.2 \%$ & 92 & $85.2 \%$ & 63 & $85.1 \%$ \\
\hline TTYL & Talk to you later & 155 & $85.2 \%$ & 89 & $82.4 \%$ & 66 & $89.2 \%$ \\
\hline$B R B^{*}$ & Be right back & 153 & $84.1 \%$ & $\overline{84}$ & $77.8 \%$ & 69 & $93.2 \%$ \\
\hline$\overline{P L Z}$ & Please & 150 & $82.4 \%$ & $\overline{86}$ & $79.6 \%$ & 64 & $86.5 \%$ \\
\hline IDK & I don't know & 147 & $80.8 \%$ & 84 & $77.8 \%$ & 63 & $85.1 \%$ \\
\hline L8R & Later & 146 & $80.2 \%$ & 83 & $76.9 \%$ & 63 & $85.1 \%$ \\
\hline$J K^{*}$ & Just kidding & 140 & $76.9 \%$ & 76 & $70.4 \%$ & 64 & $86.5 \%$ \\
\hline LMAO** & Laughing my ass off & 128 & $70.3 \%$ & 82 & $75.9 \%$ & 46 & $62.2 \%$ \\
\hline$S R Y^{* *}$ & Sorry & 125 & $68.7 \%$ & 68 & $63.0 \%$ & 57 & $77.0 \%$ \\
\hline$T H X^{*}$ & Thanks & 124 & $68.1 \%$ & 65 & $60.2 \%$ & 59 & $79.7 \%$ \\
\hline MSG & Message & 121 & $66.5 \%$ & 77 & $71.3 \%$ & 44 & $59.5 \%$ \\
\hline$B / F$ & Boyfriend/Best friend & 114 & $62.6 \%$ & 73 & $67.6 \%$ & $\overline{41}$ & $55.4 \%$ \\
\hline$G F$ & Girlfriend & 113 & $62.1 \%$ & 62 & $57.4 \%$ & 51 & $68.9 \%$ \\
\hline$U R^{*}$ & Your or you're & 111 & $61.0 \%$ & 54 & $50.0 \%$ & 57 & $77.0 \%$ \\
\hline CUL8R & See you later & 108 & $59.3 \%$ & 59 & $54.6 \%$ & 49 & $66.2 \%$ \\
\hline RUOK? & Are you okay? & 97 & $53.3 \%$ & 52 & $48.1 \%$ & 45 & $60.8 \%$ \\
\hline$C U^{* *}$ & See you & 96 & $52.7 \%$ & 50 & $46.3 \%$ & 46 & $62.2 \%$ \\
\hline$N P$ & No problem & 74 & $40.7 \%$ & 40 & $37.0 \%$ & 34 & $45.9 \%$ \\
\hline MYOB & Mind your own business & 71 & $39.0 \%$ & $\overline{40}$ & $37.0 \%$ & 31 & $41.9 \%$ \\
\hline WRUD & What are you doing? & 65 & $35.7 \%$ & 34 & $31.5 \%$ & 31 & $41.9 \%$ \\
\hline
\end{tabular}




\begin{tabular}{|c|c|c|c|c|c|c|c|}
\hline MorF & Male or female & 50 & $27.5 \%$ & 28 & $25.9 \%$ & 22 & $29.7 \%$ \\
\hline$B B S$ & Be back soon & 46 & $25.3 \%$ & 24 & $22.2 \%$ & 22 & $29.7 \%$ \\
\hline WTG & Way to go & 42 & $23.1 \%$ & 21 & $19.4 \%$ & 21 & $28.4 \%$ \\
\hline F2F & Face to face & 40 & $22.0 \%$ & 23 & $21.3 \%$ & 17 & $23.0 \%$ \\
\hline$\overline{H R U}$ & How are you? & 36 & $19.8 \%$ & 18 & $16.7 \%$ & 18 & $24.3 \%$ \\
\hline$\overline{A T M}$ & At the moment & 25 & $13.7 \%$ & 13 & $12.0 \%$ & 12 & $16.2 \%$ \\
\hline DHTS & Don't have the money & 21 & $11.5 \%$ & 16 & $14.8 \%$ & 5 & $6.8 \%$ \\
\hline IMO & In my opinion & 19 & $10.4 \%$ & 14 & $13.0 \%$ & 5 & $6.8 \%$ \\
\hline$B 4 N$ & Bye for now & 17 & $9.3 \%$ & 11 & $10.2 \%$ & $\overline{6}$ & $8.1 \%$ \\
\hline$\overline{C B}$ & Call back & 14 & $7.7 \%$ & 10 & $9.3 \%$ & 4 & $5.4 \%$ \\
\hline SUL & See you later & 13 & $7.1 \%$ & 10 & $9.3 \%$ & 3 & $4.1 \%$ \\
\hline$\overline{U W}$ & You're welcome & 12 & $6.6 \%$ & 8 & $7.4 \%$ & $\overline{4}$ & $5.4 \%$ \\
\hline RFL?** & Ready for lunch? & 7 & $3.8 \%$ & 7 & $6.5 \%$ & 0 & $0.0 \%$ \\
\hline IHMB & I hate my boss & 6 & $3.3 \%$ & 6 & $5.6 \%$ & 0 & $0.0 \%$ \\
\hline CTRN & Can't talk right now & 5 & $2.7 \%$ & $\overline{2}$ & $1.9 \%$ & 3 & $4.1 \%$ \\
\hline NCIH & No chance in hell & 4 & $2.2 \%$ & 1 & $0.9 \%$ & 3 & $4.1 \%$ \\
\hline POS & Parent over shoulder & 3 & $1.6 \%$ & 0 & $0.0 \%$ & 3 & $4.1 \%$ \\
\hline WRUV4? & Who are you voting for? & 3 & $1.6 \%$ & 1 & $0.9 \%$ & 2 & $2.7 \%$ \\
\hline TMB & Text me back & 2 & $1.1 \%$ & 2 & $1.9 \%$ & $\overline{0}$ & $0.0 \%$ \\
\hline OTTOMH & Off the top of my head & 1 & $0.5 \%$ & 1 & $0.9 \%$ & 0 & $0.0 \%$ \\
\hline WFM & Works for me/wait for me & 1 & $0.5 \%$ & 1 & $0.9 \%$ & 0 & $0.0 \%$ \\
\hline
\end{tabular}

* Significant at a $95 \%$ confidence level $(\alpha=.05)$ using two-tailed z-test for proportions

** Significant at a $90 \%$ confidence level $(\alpha=.10)$

\section{REFERENCES}

1. Behairy, N., Mukherjee, S., Ertimur, B., and Venkatesh, A. (2006). Technology-based communication patterns of youth. Advances in Consumer Research, 33, 304-305.

2. Chat abbreviations (2006). Retrieved May 1, 2006, from http://www.mistupid.com/ internet/chattalk.htm.

3. CTIA. (2007). 100 wireless quick facts. Retrieved October 1, 2007, from http://www.ctia.org/content/index/cfm/AID/1038 6.

4. Dictionary of Instant Messaging Acronyms (2006). Retrieved August 30, 2006, from http://www.studentslackers.com/im.htm.

5. Dolan, P. (2008) Is Txting 4 U? Doctors let fingers do the talking. Retrieved February 24, 2008, from http://www.amaassn.org/amednews/2008/02/04/bisa0204.htm.

6. FAQ User's Guide: What does all this chat room slang mean? (2006). Retrieved May 1, 2006, from http://www.pulpchat.com/faq/faq215.php.

7. Genn, A. (2005, September 16). In the workplace, instant messaging/text messaging language doesn't work. Long Island Business News. pg. 1.
8. Gross, E. (2004). Adolescent Internet use: What we expect, what teens report. Journal of Applied Developmental Psychology, 25(6), 633-649.

9. Holson, L. (2008, March 9). Text generation gap: U R 2 Old (JK). Retrieved March 10, 2008, from http://www.nytimes.com/2008/03/09/business/09 cell $/ \mathrm{html}$

10. Instant messaging applications expand (2006). Credit Union Executive Newsletter, 32(18), 6-7.

11. Internet Slang and Dictionary Translator (2008). Retrieved February 24, 2008, from http://www.noslang.com/index.php.

12. Jacobson, D. (2007). Interpreting instant messaging: context and meaning in computermediated communication. Journal of Anthropological Research, 63, 359-381.

13. List of Acronyms \& text messaging shorthand (2006). Retrieved August 30, 2006, from http://www.netlingo.com/emailsh.cfm.

14. MacSweeney, G. (2003). R U ready 4 IM? Insurance and Technology, 28(3), 36(4).

15. Malala, J. (2006). Making the case for formalizing the lingo and acronyms of virtual environments communication to meet global demands. Paper presented at the annual conference of the International academy of Linguistics, Behavioral and Social Sciences. Eric document ED 496128. 
16. Mandel, D., and Muncer, S. (2007). Control over social interactions: An important reason for young people's use of the Internet and mobile phones for communication. CyberPsychology \& Behavior 10(1), 137-140.

17. Omnipod releases survey results of most commonly used instant messaging acronyms in the workplace. (2003, December 29). Retrieved May 1, 2006, from http://www.omnipod.com/resources/press_release $\mathrm{s} / \mathrm{dec}$ acronym_survey03.shtml.

18. Omnipod releases new survey results of most commonly used instant messaging acronyms in the workplace. (2004, December 29). Retrieved May 1, 2006, from http://www.omnipod.com/resources/press_release $\mathrm{s} / \mathrm{dec}$ acronym survey04.shtml.

19. Prater, D. (2007, December 9). Tech-savvy teens talk texting. Opelika-Auburn News (AL). Retrieved using Newspaper Source database.

20. Shorthand (2006). Retrieved August 30, 2006, from http://www.netlingo.com/ lookup.cfm?term=shorthand.

21. Text messaging abbreviations (2006). Retrieved September 9, 2006, from http://www.webopedia.com/quick_ref/textmessag eabbreviations.asp.

22. Text messaging background (2008). Retrieved February 25, 2008, from http://www.cellsigns.com/industry.shtml.

23. Textonyms give cell phone addicts a new language. (2008). Reuters. Retrieved February 14, 2008, from http://www.eweek.com/ c/a/Messaging-and-Collaboration/TextonymsGive-Cell-Phone-Addicts -a-new-language/.

24. Valkenburg, P., Schouten, A., and Peter, J. (2005). New Media \& Society, 7(3), 383-402.

25. Van den Eijnden, R., Meerkerk, G., Vermulst, A., Spijkerman, R., and Engels, R. (2008). Online communication, compulsive Internet use, and psychosocial well-being among adolescents: A longitudinal study. Developmental Psychology, 44(3), 655-665.

26. Wethe, D. (2007, July 29). Cellphone users reap benefits of texting: More uses found for messaging as its popularity soars. Knight Ridder Tribune Business News. Washington, pg. 1.

27. What does all this chat room slang mean? (2006). Retrieved May 1, 2006, from http://www.pulpchat.com/faq/faq214.php.

28. Widhalm, S. (2008, January 24). OMG; how 2 know wen 2 writ $\mathrm{n}$ lingo? The Washington Times. Retrieved using Newspaper Source database.
29. Z-Test for Two Proportions (2005). Dimension Research, Inc. Retrieved March 21, 2008 from http://www.dimensionresearch.com/resources/cal culators/ztest.html.

30. Zhou, L., and Zhang, D. (2005). A heuristic approach to establishing punctuation convention in instant messaging. IEEE Transactions on Professional Communication, 48(4), 391-400. 